\section{Atomic Absorption Spectrophotometric Determination of Molybdenum and Strontium}

RECENT work reported by Menzies ${ }^{1}$ and Robinson ${ }^{2}$ has suggested that atomic absorption flame methods ${ }^{3,4}$ are not applicable to the determination of molybdenum and that the limit of strontium determination lies between 2 and 10 p.p.m. in solution.

Using a 10-cm. air-acetylene burner, a scale expansion device (suggested by Dr. J. B. Willis) and a modulated single-beam system ${ }^{5}$, it has been found that the limits of estimation of molybdenum and strontium in solutions free from interfering ions are about 0.5 and 0.05 p.p.m. respectively. Molybdenum $3132 \AA .\left(a^{7} S-y^{7} P^{0}\right)$ was the strongest in absorption of the nine absorbing molybdenum lines found. Strontium measurements were carried out on strontium $4607 \AA$. The gain in sensitivity for strontium over those previously reported is a direct result of stability of hollow cathode emission, the use of a long burner and the use of an expanded scale on the measuring unit reading $0-20$ per cent absorption over full scale. The determination of molybdenum was achieved by adjustment of the air and acetylene pressures to give reducing conditions in the flame and passage of the beam from the hollow cathode discharge tube through the flame at a point just above the cone of unburnt gases.

The concentration of free ground-state atoms of molybdenum in the flame was found to be critically dependent on the proportions of air and acetylene. No perceptible absorption resulted from spraying a 50 p.p.m. molybdenum (ammonium molybdate) solution into an air-rich flame, whereas adjustment of the proportion of air to acetylene to give a flame in which yellowing due to incandescent carbon particles was just visible at the base gave an absorption of 35 per cent. Provided that the beam from the hollow cathode tube was confined to the lowest possible level in the flame, no great gain in sensitivity resulted from the use of a highly luminous flame. Despite this dependence on reducing conditions, the presence of an oxidizing agent in the sample solution did not cause serious depression of molybdenum absorption (compare cols. 3 and 4, Table 1 ). The presence of the large excesses of extraneous elements in the samples examined had a greater effect than did nitric acid (compare cols. 4 and 5, Table 1), but this effect was not so great as to cause difficulty in analysis due to loss of sensitivity.

The results in column 5 of Table 1 were obtained by use of the 'addition' method. 'This procedure has

Table 1. Concentrations of molybdenum in samples of molybdenized superphosphate (nominally $1.5 \mathrm{oz}$. nolybdenum trioxide per cwt.) and stainless steel as calculated from atomic absorption analysis against standards in water, in $0.82 N$ nitric acid and by the addition
method. The analyses were carried out directly on portions of $200-\mathrm{ml}$. method. The analyses were carried out directly on portions of $200-\mathrm{ml}$. inal volumes of nitric-hydrochloric acid

\begin{tabular}{|c|c|c|c|c|}
\hline Sample & $\begin{array}{l}\text { Weight } \\
\text { taken } \\
\text { (gm.) }\end{array}$ & $\begin{array}{r}\text { Apparen } \\
\text { denum con } \\
\text { usi } \\
\text { Standards } \\
\text { in water } \\
\text { (per cent) }\end{array}$ & $\begin{array}{l}\text { t molyb- } \\
\text { centration } \\
\text { ng } \\
\mid \begin{array}{c}\text { Standards } \\
\text { in nitric } \\
\text { acid } \\
\text { (per cent) }\end{array}\end{array}$ & $\begin{array}{l}\text { Molybdenum } \\
\text { concentration } \\
\text { by addition } \\
\text { method } \\
\text { (per cent) }\end{array}$ \\
\hline $\begin{array}{r}\text { Superphosphate } \\
(1) \\
(2) \\
(3) \\
\text { Stainless steel }(1) \\
(2)\end{array}$ & $\begin{array}{c}8 \cdot 42 \\
10 \cdot 0 \\
10 \cdot 0 \\
2 \cdot 930 \\
2 \cdot 933\end{array}$ & $\begin{array}{l}0 \cdot 0317 \\
0 \cdot 0366 \\
0 \cdot 0366 \\
0 \cdot 159 \\
0 \cdot 171\end{array}$ & $\begin{array}{l}0 \cdot 0356 \\
0 \cdot 0412 \\
0 \cdot 0412 \\
0 \cdot 179 \\
0 \cdot 192\end{array}$ & $\begin{array}{l}0 \cdot 0575 \\
0 \cdot 0555 \\
0 \cdot 0526 \\
0.266 \\
0 \cdot 278\end{array}$ \\
\hline
\end{tabular}

been used in arc emission determination ${ }^{6,7}$ of trace elements in samples of widely variable major element composition. However, poor precision and uncertainty regarding linearity of the relationship between emitted intensity and concentration impairs its value in are analysis. Provided the equation of a non-linear curve is known, the use of the addition method is possible, but tedious.

By taking three equal aliquots of a sample solution, adding equal volumes of water to one and solutions containing known concentrations of the analysis element to the other two, then analysing all three using the apparatus described, it was found that the relationship between percentage absorption and concentration was linear up to about 15 per cent absorption. This test has been carried out for molybdenum in the samples cited in Table 1, for strontium in ammonium chloride extracts of soils and in nitricperchloric-sulphuric acid digests of plant material and for calcium in solutions for microbiological culture.

The addition method was found essential to the analysis of plants for strontium because measurements on synthetically prepared solutions indicated that the interferences would be so difficult to control that the results of analysis against orthodox standards would be unreliable. Advantage may be gained from the general application of the addition method to atomic absorption analysis because, in using it, both sample and 'standard' are measured under exactly the same conditions of viscosity, surface tension and chemical interference and because modulated atomic absorption apparatus cannot measure anything but atoms of the analysis element in the flame.

Although insufficient sensitivity has been attained, as yet, in the direct atomic absorption analysis of solutions from plants and soils for molybdenum, the results in Table 1 indicate that advantages can be gained from its application to such analytical fields as those of the fertilizer and metallurgical industries. The specificity of the atomic absorption method employing a modulated system for measurement of the element sought gives it obvious advantages over flame emission methods in the analysis of soils, plants, bones and the like for natural strontium in 'fall-out' studies.

The results for molybdenum suggest the possibility of using reducing flame conditions to make possible atomic absorption analysis for other elements. They also suggest that further gains in sensitivity may result not only from designing burners to give hightemperature flames, but also from designing them to produce highly reducing conditions in the flame.

The apparatus used and the results of these and further investigations will be described in detail elsewhere.

\section{J. DAvin}

Division of Plant Industry,

Commonwealth Scientific and

Industrial Research Organization, Canberra.

1 Menzies, A. C., Anal. Chem., 32, 898 (1960).

Robinson, J. W., Anal. Chem., 32, No. 8, 17.4 (1960).

${ }^{3}$ Walsh, A., Spectrochim. Acta, 7, 108 (1955).

'Russell, B. J., Shelton, J. P., and Walsh, A., Spectrochim. Acta, 8, $317(1957)$.

Box, G. F., and Walsh, A., Spectrochim. Acta, 16, 255 (1960).

- Oertel, A. C., Aust. J. A pp. Sci., 1, 259 (1950).

- Foster, J. S., and Horton, C. A., Proc. Roy. Soc., H, 123, 422 (1937). 